\title{
Splenectomy before adult liver transplantation: a retrospective study
}

\author{
LingXiang Kong, Ming Li, Lei Li, Li Jiang, Jiayin Yang ${ }^{*}$ and Lvnan Yan
}

\begin{abstract}
Background: A considerable number of patients with portal hypertension (PHT) have to undergo splenectomy because they do not meet the requirements for liver transplantation (LT) or cannot find a suitable liver donor. However, it is not known whether pre-transplantation splenectomy may create occult difficulties for patients who require $L T$ in future.

Methods: We analyzed 1059 consecutive patients who underwent adult liver transplantation (ADLT). Patients with pre-transplantation splenectomy $\mathrm{Sp}(+)$ and without splenectomy $\mathrm{Sp}(-)$ were compared using a propensity score analysis to create the best match between groups.

Results: There were no differences between patients in group $\mathrm{Sp}(+)$ and group $\mathrm{Sp}(-)$ with respect to the main post-operative infections (12.20\% vs. $15.85 \%, P=0.455)$, and the incidence of major complications $(6.10 \%$ vs. $10.98 \%$, $P=0.264)$. The post-operative platelet count was significantly higher in group Sp $(+)(P=0.041)$, while group Sp $(-)$ had a higher rate of post-operative thrombocytopenia ( $91.46 \%$ vs. $74.39 \%, P=0.006)$ and early allograft dysfunction (EAD) $(23.20 \%$ vs. $10.98 \%, P=0.038)$. The 5 -year overall survival rates were similar in groups $\mathrm{Sp}(-)$ and $\mathrm{Sp}(+)(69.7 \%$ vs. $67.6 \%, P=0.701)$.

Conclusions: Compared with Sp(-), the risk of infection and post-operative complications in group Sp(+) was not increased, while group Sp(-) had a higher rate of post-operative EAD. Moreover, pre-transplantation splenectomy is very effective for the prevention of thrombocytopenia after LT. Pre-transplantation splenectomy is recommended in cases with risky PHT patients without appropriate source of liver for LT.
\end{abstract}

Keywords: Splenectomy, Liver transplantation, Thrombocytopenia, Early allograft dysfunction

\section{Background}

The incidence of PHT with post-hepatitis cirrhosis is higher in China than elsewhere worldwide [1]. Early complications caused by increased portal pressure, such as variceal hemorrhage, can be treated with vein ligation under endoscopy and injection; however, it is mandatory to switch to decompressive shunt procedures if endoscopic therapy fails to control recurrent variceal hemorrhage [2].

With the advent of LT, simple symptomatic treatment is no longer used for end-stage liver disease, but radical treatment by LT is often performed, greatly increasing the survival rate of patients with end-stage liver disease. Liver diseases are frequently accompanied by PHT, and splenectomy is one of the basic means of treatment of this

\footnotetext{
* Correspondence: yangjygyz@163.com

Department of Liver Surgery, West China Hospital of Sichuan University, Chengdu, Sichuan Province, China
}

condition. However, given the great number of patients with end-stage liver disease, a considerable number of patients would require splenectomy to reduce portal pressure, because they do not meet the requirements for transplantation or cannot find suitable liver donor. Splenectomy plays a significant role in improving the survival of patients and can create precious time for subsequent treatment. However, it is not known whether splenectomy may create In the past, many scholars stated their views with regard to this point. Starzl et al. [3] were the first to suggest the role of splenectomy in the prolongation of allograft survival, as four of their five patients treated with thymectomy and splenectomy maintained their renal function for almost 6 months. Later, Hume et al. suggested that splenectomy, if performed prior to or at the time of transplantation, could improve leukocyte count and permit administration of large 
doses of azathioprine (AZA). With a view to preventing thrombocytopenia, and when using AZA after transplantation, splenectomy was often considered as a preventive surgery. With the discovery of cyclosporine and is application after liver transplant, preoperative or intraoperative splenectomy for liver transplant patients has become rather controversial, and is no longer a routine surgery. In addition, Troisi et al. [4] observed that massive ascites loss was associated with extremely high portal flow and histologically proven graft congestion. Splenectomy reduces the portal flow, resolving the ascites problem. However, a relative increase in mesenteric blood flow, containing nutrientrich blood [5], or a reduction in liver congestion can contribute to liver regeneration [6]. Moreover, patients with hepatitis $\mathrm{C}$ virus (HCV) are commonly treated with interferons. Hirotaka et al. [7] have suggested that, to complete pre-emptive interferon therapy, which is initiated approximately 2 months after the operation, splenectomy should be performed simultaneously with $\mathrm{LT}$ in $\mathrm{HCV}$ patients with a platelet count of $<60 / \mathrm{L}$.

At present, even though there are many related reports, there is no consensus on pre-transplantation splenectomy and current LT standards for hepatocarcinoma (HCC) also lack a description of such patients, such as Milan criteria [8], UCSF criteria [9], Hangzhou criteria [10] and BCLC criteria [11]. Therefore, we studied a series of patients at our institution. We here report the results of a retrospective analysis of adult liver transplant patients who had undergone splenectomy.

\section{Methods}

In our study, the grafts for LT were from donation after cardiac death. No prisoners were included as donors. The protocol was approved by the Ethics Committee of the West China Hospital of Sichuan University West China Hospital. Written informed consent was obtained from all the recipients prior to their surgery, and all of donations were voluntary and altruistic in all cases, and were in accordance with the ethical guidelines of the Declaration of Helsinki.

\section{Patients}

Figure 1 shows the inclusion and exclusion criteria used for establishing the study cohort. Based on the different preoperative intervention methods, they were initially divided into 2 groups: $\mathrm{Sp}(-)$ group, which consisted of patients who underwent LT without preoperative splenectomy and the $\mathrm{Sp}(+)$, which consisted of those who underwent splenectomy before LT. The indication in our study for splenectomy was progressive, invalidating and/or risky PHT (large splenomegaly, hypersplenism with platelet and/or polymorphonuclear cells count less than $100 \mathrm{Giga} / \mathrm{L}$ and 4

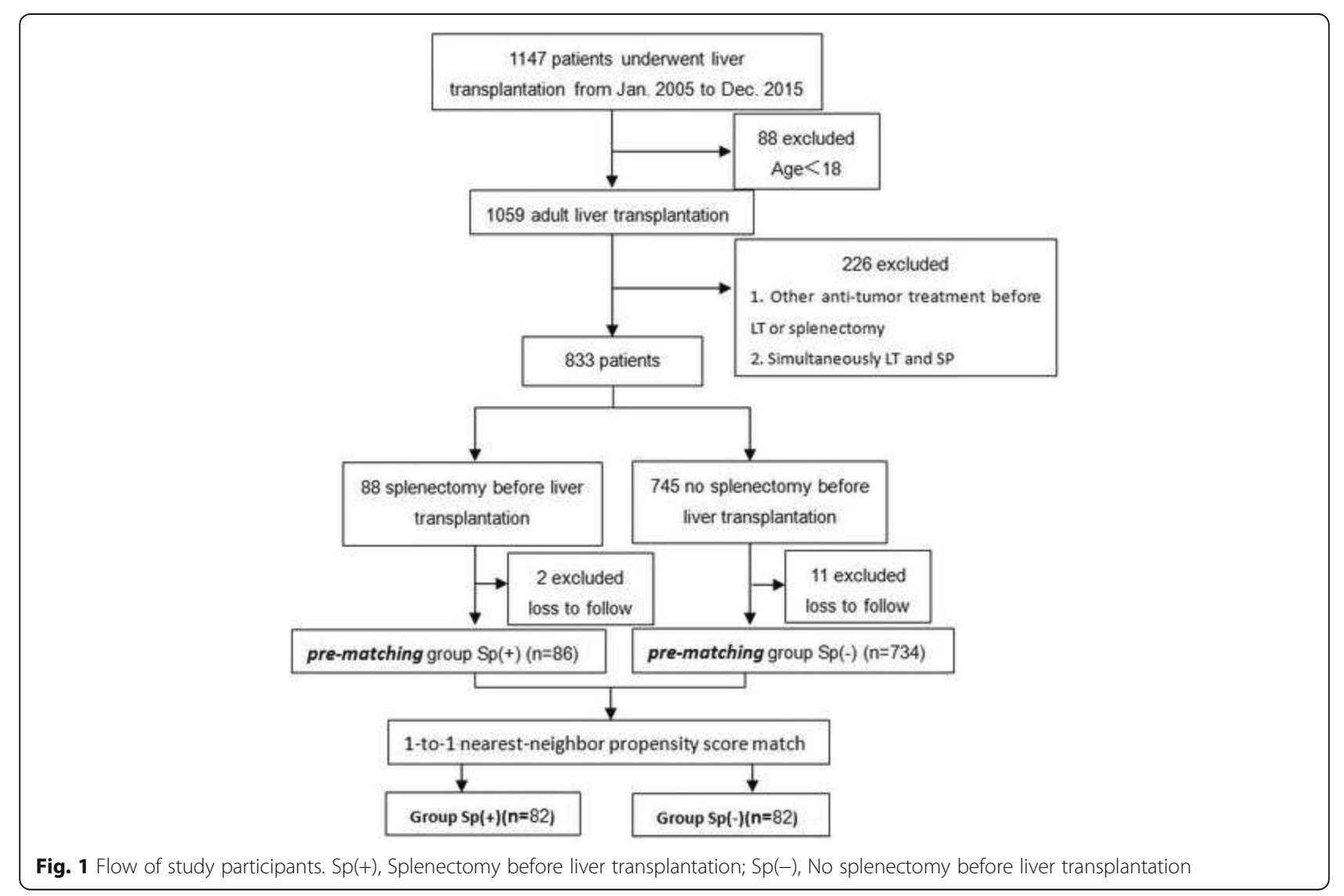


Giga/L respectively, grade II or more esophageal varices with the presence of red signs or previous bleeding) in patients with preserved liver and lung function [12]. Disease features and perioperative characteristics of patients when they underwent pre-transplant splenectomy were summarized in Additional file 1: Table S1. All patients were treated with only total splenectomy without partial splenectomy or anther surgery. The indication for LT in our study was endstage liver diseases [13]. All HCC patients in our study were without vascular invasion and extra hepatic metastasis and summarized in Table 1.

To ensure the consistency of baseline data, none of the enrolled patients received any other therapies before surgery. All hepatitis B virus (HBV) DNA-positive patients were treated with anti-viral therapy before and after surgery. They were monitored until Dec. 2015 or until their death, and their medical records were retrospectively reviewed. Clinical and demographic data of donors and recipients were collected from the records of the Chinese Liver Transplant Registry (http://cltr.cotr.cn), and patient demographics, disease features, perioperative course, and long-term outcomes were compared between group $\mathrm{Sp}(+)$ and group $\mathrm{Sp}(-)$ patients.

\section{Definitions}

The Clavien-Dindo complication classification [13] system was used for post-operative complication grading and grade III-IV complications were defined as severe complications. Clinically relevant PHT is defined as the presence of esophageal varices and/or a platelet count of less than 100,000 per $\mathrm{mL}$ in association with splenomegaly [14]. EAD defined as the presence of one or more of the following postoperative laboratory: bilirubin $\geq 10 \mathrm{mg} / \mathrm{dL}$ on day 7 , international normalized ratio $\geq 1.6$ on day 7 ,

Table 1 Baseline demographic and disease features characteristics in the two groups

\begin{tabular}{|c|c|c|c|c|c|c|}
\hline \multirow[t]{2}{*}{ Variables } & \multicolumn{2}{|c|}{ Before matching } & \multirow[t]{2}{*}{$P$ value } & \multicolumn{2}{|l|}{ After matching } & \multirow[t]{2}{*}{$P$ value } \\
\hline & $S p+(n=86)$ & $S p-(n=734)$ & & $S p+(n=82)$ & $\mathrm{Sp}-(n=82)$ & \\
\hline \multicolumn{7}{|l|}{ Donor } \\
\hline Age (mean $\pm S D$, years) & $34.38 \pm 9.46$ & $33.58 \pm 9.62$ & 0.465 & $34.13 \pm 9.39$ & $34.94 \pm 9.29$ & 0.582 \\
\hline Male (\%) & $72(83.3 \%)$ & $611(82.2 \%)$ & 0.910 & $69(84.1 \%)$ & $67(81.7 \%)$ & 0.836 \\
\hline height (mean $\pm \mathrm{SD}, \mathrm{cm}$ ) & $166.62 \pm 7.48$ & $167.82 \pm 6.69$ & 0.121 & $166.67 \pm 7.45$ & $167.10 \pm 6.21$ & 0.689 \\
\hline weight (mean $\pm S D, k g)$ & $61.56 \pm 6.45$ & $63.52 \pm 7.38$ & 0.019 & $62.00 \pm 6.29$ & $62.10 \pm 6.98$ & 0.913 \\
\hline $\mathrm{BMI}\left(\right.$ mean $\left.\pm \mathrm{SD}, \mathrm{kg} / \mathrm{m}^{2}\right)$ & $22.14 \pm 1.65$ & $22.50 \pm 2.05$ & 0.117 & $22.28 \pm 1.53$ & $22.20 \pm 1.85$ & 0.779 \\
\hline \multicolumn{7}{|l|}{ Recipient } \\
\hline Age (mean $\pm S D$, years) & $46.34 \pm 8.44$ & $44.52 \pm 9.90$ & 0.102 & $46.32 \pm 8.39$ & $46.41 \pm 9.64$ & 0.945 \\
\hline Male (\%) & $68(79.1 \%)$ & $619(84.3 \%)$ & 0.210 & $64(78.0 \%)$ & $67(81.7 \%)$ & 0.697 \\
\hline Height (mean $\pm S D, c m$ ) & $166.90 \pm 7.31$ & $167.48 \pm 6.43$ & 0.428 & $166.856 \pm 7.40$ & $167.013 \pm 7.06$ & 0.889 \\
\hline Weight (mean \pm SD, kg) & $61.60 \pm 9.55$ & $63.42 \pm 10.19$ & 0.114 & $61.67 \pm 9.49$ & $61.15 \pm 10.07$ & 0.735 \\
\hline $\mathrm{BMI}\left(\right.$ mean $\left.\pm \mathrm{SD}, \mathrm{kg} / \mathrm{m}^{2}\right)$ & $22.08 \pm 2.84$ & $22.56 \pm 3.03$ & 0.161 & $22.11 \pm 2.77$ & $21.84 \pm 2.81$ & 0.547 \\
\hline HBV (\%) & $66(76.7 \%)$ & $574(78.2 \%)$ & 0.757 & $62(75.6 \%)$ & $63(76.8 \%)$ & 0.854 \\
\hline $\mathrm{TB}($ mean $\pm \mathrm{SD}, \mu \mathrm{mol} / \mathrm{L})$ & $71.21 \pm 98.22$ & $145.73 \pm 202.27$ & 0.001 & $73.54 \pm 100.01$ & $83.45 \pm 144.73$ & 0.611 \\
\hline $\mathrm{ALT}$ (mean $\pm \mathrm{SD}, \mathrm{u} / \mathrm{L})$ & $41.54 \pm 44.57$ & $29.61 \pm 27.63$ & 0.089 & $36.61 \pm 27.09$ & $32.10 \pm 22.32$ & 0.363 \\
\hline $\mathrm{AST}$ (mean $\pm \mathrm{SD}, \mathrm{u} / \mathrm{L}$ ) & $33.04 \pm 35.75$ & $29.65 \pm 32.98$ & 0.520 & $31.81 \pm 29.18$ & $29.28 \pm 17.80$ & 0.588 \\
\hline Child-Pugh (mean \pm SD) & $8.71 \pm 1.80$ & $8.46 \pm 2.13$ & 0.302 & $8.62 \pm 1.76$ & $8.53 \pm 1.98$ & 0.751 \\
\hline Child-Pugh <10 (A and B), n (\%) & $60(69.77 \%)$ & $531(72.34 \%)$ & 0.614 & $58(70.73 \%)$ & $61(74.39 \%)$ & 0.600 \\
\hline MELD (mean \pm SD) & $14.66 \pm 6.66$ & $17.54 \pm 9.69$ & 0.001 & $14.82 \pm 6.88$ & $14.57 \pm 6.50$ & 0.816 \\
\hline Serum AFP > 400 ng/mL (n, \%) & $14(19.2 \%)$ & $141(16.3 \%)$ & 0.511 & $14(17.1 \%)$ & 15(18.3) & 0.838 \\
\hline Non-tumor $(n, \%)$ & $53(61.6 \%)$ & $416(56.7 \%)$ & 0.380 & $50(60.97)$ & $49(59.75)$ & 0.873 \\
\hline Number of tumor $=1(n, \%)$ & $27(31.4 \%)$ & $238(32.4 \%)$ & 0.395 & $27(32.9 \%)$ & $27(32.9 \%)$ & 1 \\
\hline Number of tumor $=2-3(n, \%)$ & $6(6.98 \%)$ & $80(10.9 \%)$ & 0.261 & $5(6.10 \%)$ & $6(7.32 \%)$ & 1 \\
\hline Tumor size < $3 \mathrm{~cm}(\mathrm{n}, \%)$ & $25(29.1 \%)$ & $193(26.3 \%)$ & 0.581 & $25(30.5 \%)$ & $26(31.7 \%)$ & 0.866 \\
\hline Tumor size $>3 \mathrm{~cm}(\mathrm{n}, \%)$ & $8(9.30 \%)$ & $125(17.0 \%)$ & 0.080 & $7(8.54 \%)$ & $6(7.32 \%)$ & 0.773 \\
\hline Tumor differentiation grade I, II (n, \%) & $15(17.4 \%)$ & $140(19.1 \%)$ & 0.714 & $15(18.3 \%)$ & $14(17.1 \%)$ & 0.897 \\
\hline Tumor differentiation grade III (n, \%) & $18(20.9 \%)$ & $178(24.3)$ & 0.494 & $17(20.7 \%)$ & $19(23.2 \%)$ & 0.706 \\
\hline
\end{tabular}


and alanine or aspartate aminotransferases $>2000 \mathrm{IU} / \mathrm{L}$ within the first 7 days [15].

\section{Statistical analysis}

SPSS 18.0 statistical software (SPSS Inc., Chicago, IL, USA) was used to analyse the relevant data. SPSS 18 did not have a stand-alone function for propensity score analysis, but after the R software and plug-in that could link with the corresponding versions of SPSS and propensity score matching package were installed, propensity score matching could be accomplished by SPSS software [16]. To minimize the influence of other confounders on outcome, we used a propensity score analysis to match $\mathrm{Sp}(+)$ patients with $\mathrm{Sp}(-)$ patients. $\mathrm{Sp}(+)$ patients was matched in a 1:1 ratio with $\mathrm{Sp}(-)$ patients using the nearest neighbor matching and based on the variables listed in Table 1. Categorical data were presented as number (per cent) and compared using Pearson chi-Square, Fisher's exact test. Continuous variables were expressed as the mean value \pm SD and analyzed using t-test and repeated measure analysis of variance. Overall patient survival was estimated by the Kaplan-Meier method, and differences between two groups were determined by log-rank test. Independent factors for the platelet count and overall survival were analyzed by multiple regression and Cox proportional hazards models, respectively. $P<0.05$ was considered statistically significant.

\section{Results}

Baseline demographic and disease features characteristics A total of 1147 patients underwent LT between January 2005 and December 2015 at our center. After excluding 11 patients who were lost to follow-up, 734 patients who had not undergone splenectomy before transplantation were retained in pre-matching group $\mathrm{Sp}(-)$. After excluding 2 patients who were lost to follow-up, 86 patients who underwent preoperative splenectomy before transplantation were finally included in pre-matching group $\mathrm{Sp}(+)$. we used a propensity score analysis to match $\mathrm{Sp}(+)$ patients with $\mathrm{Sp}(-)$ patients. $\mathrm{Sp}(+)$ patients $(n=82)$ was matched in a 1:1 ratio with $\mathrm{Sp}(-)$ patients $(n=82)$ using the nearest neighbor matching and based on the variables listed in Table 1.

The baseline characteristics and disease features of $\mathrm{Sp}(-)$ and $\mathrm{Sp}(+)$ in the pre-match and post-match samples are summarized in Table 1 . In the pre-match model, a total of 820 cases were selected to meet the criteria of $\mathrm{Sp}(+)$ and $\mathrm{Sp}(-)$ group. All cases were 18 years of age or older. In the post-match model, the differences in all variables between $\mathrm{Sp}(+)$ and $\mathrm{Sp}(-)$ patients were reduced and were therefore not statistically significant. Because period of time after splenectomy may influence the prognosis of LT. We compared the period ( $\leq 6$ and $>6$ months) from splenectomy to LT in group $\mathrm{Sp}(+)$ (Fig. 2). There is no significant difference of 1-, 3-, and 5-year OS rates between the two groups $(71.0 \%$ vs.77.4\% $P=0.839 ; 71.0 \%$ vs. $72.3 \%$,

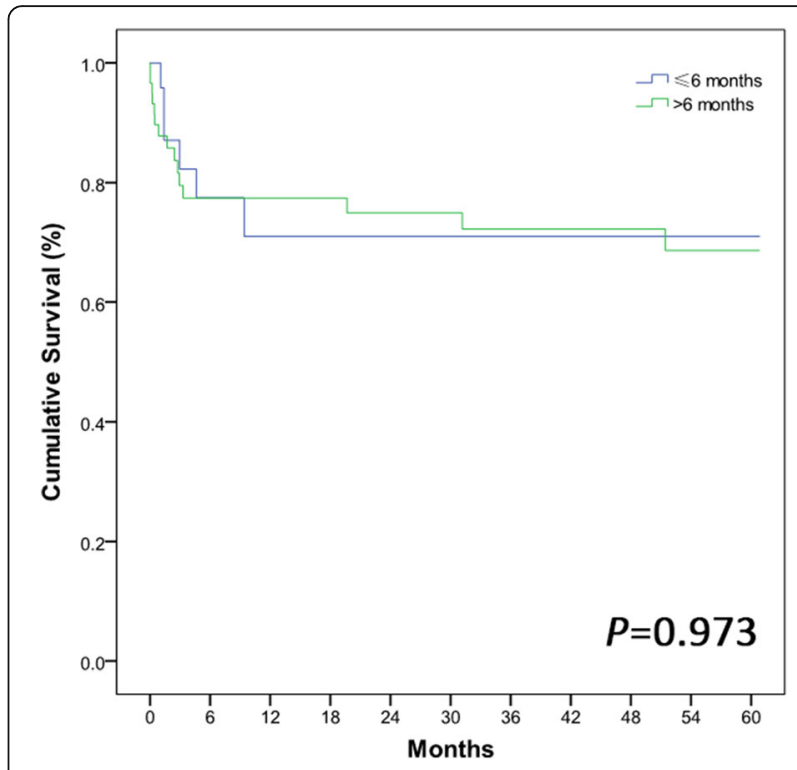

Fig. 2 Group $S p(+)$ are divided into two groups according to the period ( $\leq 6$ and $>6$ months) from splenectomy to liver transplantation. There is no significant difference of 1-, 3-, and 5-year OS rates between the two groups $(71.0 \%$ vs.77.4\% $P=0.839 ; 71.0 \%$ vs. $72.3 \%, P=0.992$; $71.0 \%$ vs. $68.6 \%, P=0.973)$

$P=0.992 ; 71.0 \%$ vs. $68.6 \%, P=0.973)$. The result of single factor analysis with regard to the period from splenectomy to LT related to 5 -years OS rates is also not statistically significant $(P=0.271)$.

\section{Surgical characteristics, post-operative course and survival}

Perioperative course post-match samples are summarized in Table 2. There was no significant difference in blood loss during the operation, warm ischemia time and GRWR between group $\mathrm{Sp}(+)$ and group $\mathrm{Sp}(-)$.

The post-operative course and survival were analyzed using the post-match sample summarized in Table 2. There were no differences between patients in group $\mathrm{Sp}(+)$ and group $\mathrm{Sp}(-)$ in terms of major infections including lung infection, urinary tract infection, positive blood culture $(12.20 \%$ vs. $15.85 \%, P=0.455)$, the incidence of major complications (Clavien-Dindo $\geq$ Grade 3; $6.10 \%$ vs. $10.98 \%, P=0.264$ ), and no portal vein thrombosis in both groups. No difference existed between the two groups with regard to 90 days mortality $(P=0.243)$. The length of post-operative hospital stay were similar in group $\mathrm{Sp}(+)$ and group $\mathrm{Sp}(-)$. In addition, we also analyzed the relationship between group $\mathrm{Sp}(-)$ and group $\mathrm{Sp}(+)$ with regard to the platelet count and found that group $\mathrm{Sp}(-)$ has a higher rate of post-operative thrombocytopenia $(91.46 \%$ vs. $74.39 \%, P=0.006)$, and more EAD than $\mathrm{Sp}(+)(23.20 \%$ vs. $10.98 \%, P=0.038)$. The platelet count was significantly higher in group $\mathrm{Sp}(+)$ than in group $\mathrm{Sp}(-)$ (Fig. 3, $P=0.041$ ). Independent 
Table 2 Perioperative course and postoperative outcome

\begin{tabular}{|c|c|c|c|}
\hline Variables & $\mathrm{Sp}+(n=82)$ & $S p-(n=82)$ & $P$ value \\
\hline GRWR (mean \pm SD) & $1.68 \pm 0.52$ & $1.65 \pm 0.66$ & 0.739 \\
\hline Warm ischemia time (mean $\pm S D, \min )$ & $5.88 \pm 6.95$ & $4.66 \pm 4.10$ & 0.171 \\
\hline Intraoperative blood loss (mean $\pm \mathrm{SD}, \mathrm{mL}$ ) & $1478.29 \pm 317.40$ & $1571.95 \pm 598.78$ & 0.213 \\
\hline Operation time (mean \pm SD, hours) & $9.30 \pm 2.49$ & $9.07 \pm 2.16$ & 0.536 \\
\hline $\begin{array}{l}\text { Postoperative major complications } \\
\text { (Clavien-Dindo } \geq \text { Grade } 3 \text { ) (\%) }\end{array}$ & $5(6.10 \%)$ & $9(10.98 \%)$ & 0.264 \\
\hline $\begin{array}{l}\text { Postoperative infection (\%) } \\
\text { Mortality ( } 90 \text { days) }\end{array}$ & $\begin{array}{l}10(12.20 \%) \\
13(15.9 \%)\end{array}$ & $\begin{array}{l}13(15.85 \%) \\
8(9.76 \%)\end{array}$ & $\begin{array}{l}0.455 \\
0.243\end{array}$ \\
\hline Postoperative portal vein thrombosis (\%) & 0 & 0 & NS \\
\hline Postoperative thrombocytopenia (\%) & $61(74.39 \%)$ & $75(91.46 \%)$ & 0.006 \\
\hline EAD (\%) & $9(10.98 \%)$ & 19(23.20\%) & 0.038 \\
\hline Length of postoperative hospital stay (mean \pm SD, days) & $15.34 \pm 1.67$ & $15.76 \pm 3.24$ & 0.269 \\
\hline
\end{tabular}

GRWR Graft/Recipient's Body Weight Ratio, EAD early allograft dysfunction

factors for the platelet count analyzed by multiple regression were summarized in Table 3. Pre-transplantation splenectomy was considered to be a protective independent factor for post-operative thrombocytopenia. $(P=0.002)$

The mean follow-up for group $\mathrm{Sp}(+)$ was 36.1 months, whereas it was 38.4 months in group $\mathrm{Sp}(-)$. Fig. 4 shows that 1-, 3-, and 5-year OS rates of 75.0, 70.8 and $67.6 \%$, respectively, in the $\mathrm{Sp}(+)$ group vs. $79.7,71.7$ and $69.7 \%$, respectively, in the $\mathrm{Sp}(-)$ group $(P=0.459$, $0.730,0.701$ respectively). Independent factors for overall survival were analyzed by Cox proportional hazards models in Table 4. Tumor related factors were considered independent risk factors for overall survival $(P=0.041)$.

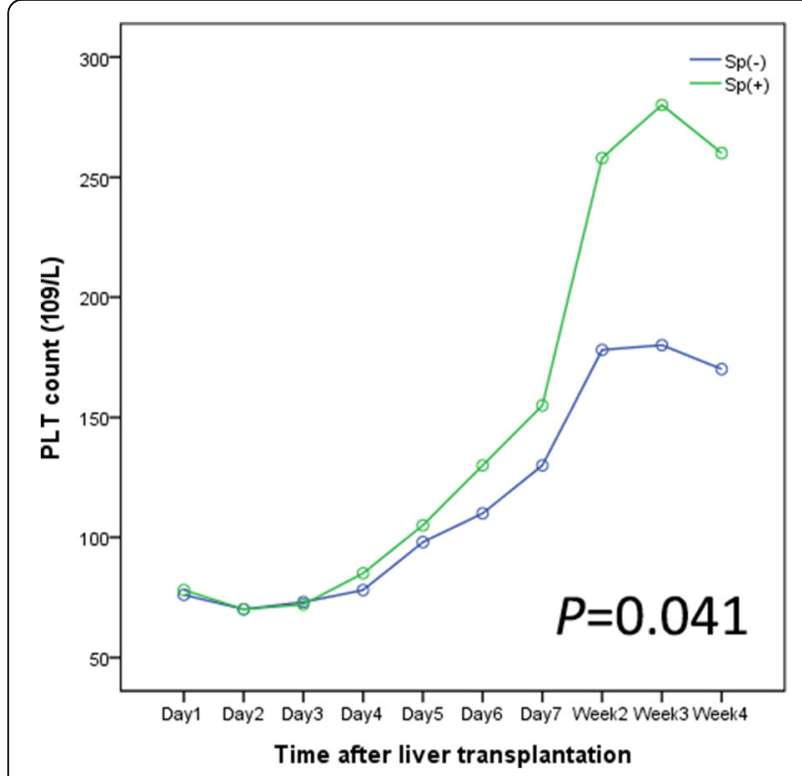

Fig. 3 Platelet count changes after liver transplantation

\section{Discussion}

At present, LT is the last choice for many patients with end-stage liver disease. The wait for transplantation is also long due to the shortage of donor organs. Moreover, LT is not feasible for all patients. Therefore, in order to reduce the pressure on the portal vein, many patients with liver disease choose to undergo splenectomy as a bridging therapy prior to LT. Thus, the influence of splenectomy on LT is still worthy of consideration.

First, the most emphasized risk conveyed by pretransplantation splenectomy is sepsis. By viewing other relevant literature, on follow-up studies of patients who underwent splenectomy for cirrhosis, but never had a LT,

Table $\mathbf{3}$ Independent variables in the multiple analysis for postoperative thrombocytopenia (post-matched $\mathrm{Sp}(+)$ and $\operatorname{Sp}(-), n=164)$

\begin{tabular}{lll}
\hline Variables & Relative risk & $P$ \\
\hline Donor & & \\
Male (\%) & -0.550 & 0.416 \\
Age & -0.003 & 0.896 \\
BMl & 0.171 & 0.265 \\
Recipient & & \\
Male (\%) & 0.658 & 0.352 \\
Age & -0.003 & 0.896 \\
BMl & 0.171 & 0.265 \\
Splenectomy & -0.1644 & 0.002 \\
MELD score & 0.052 & 0.275 \\
Child-Pugh score & 0.153 & 0.330 \\
Tumor related & -0.125 & 0.883 \\
HBV & 0.634 & 0.238 \\
GRWR & 0.024 & 0.965 \\
Warm ischemia time & 0.049 & 0.255 \\
Intraoperative blood loss & -0.001 & 0.229 \\
\hline
\end{tabular}




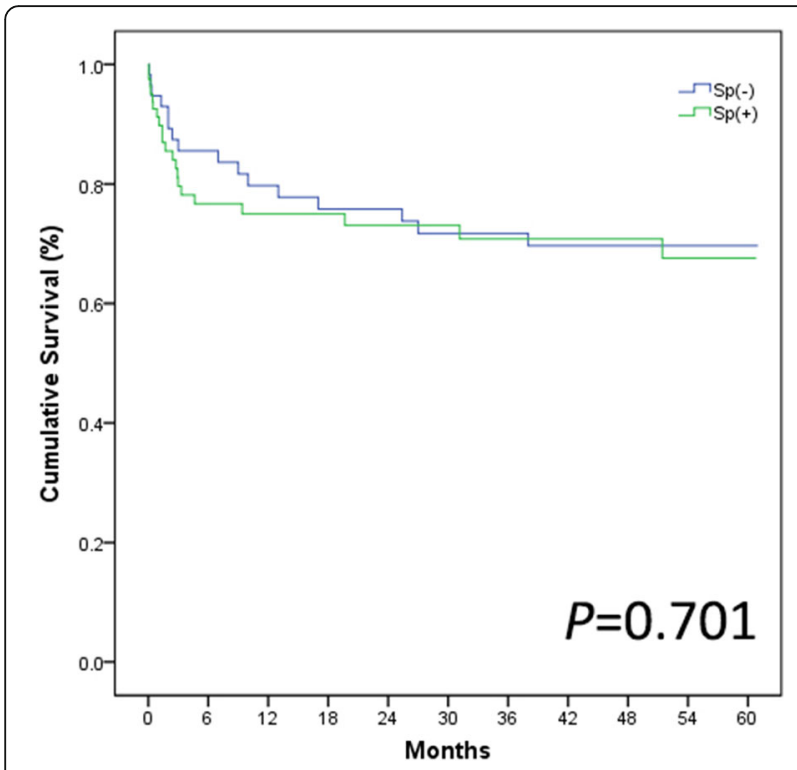

Fig. 4 5-year OS rates of the Sp(-) group and the $S p(+)$ group

A meta-analysis of follow-up studies involving 19,680 patients showed that the incidence of sepsis among adult splenectomy patients was low, and that a high mortality rate was observed only among children [17]. This metaanalysis thus suggested a low post-operative rate of sepsis after adult splenectomy. Moreover, this is the premise of a low post-operative infection rate in $\mathrm{Sp}(+)$ group. Furthermore, for patients who underwent splenectomy and LT synchronously, Samimi et al. [18] reported that synchronous splenectomy resulted in a higher mortality rate, mainly related to septic complications. However, for patients who underwent splenectomy before LT, Jeng et al. [19] and Shimadaet al. [20] found that the risk of infection after LT in patients who had undergone splenectomy remained unchanged. Our results confirm that for the patients who underwent splenectomy before LT (group $\mathrm{Sp}(+))$,the risk of infection was not increased.

Table 4 Independent variables in the Cox analysis for overall survival (post-matched Sp(+) and Sp(-), $n=164$ )

\begin{tabular}{lll}
\hline Variables & Relative risk & $P$ \\
\hline Splenectomy & 0.191 & 0.609 \\
Serum AFP & $<0.001$ & 0.818 \\
MELD score & -0.038 & 0.294 \\
Child-Pugh score & 0.186 & 0.157 \\
Tumor related & 0.803 & 0.041 \\
HBV & -0.783 & 0.054 \\
GRWR & -0.009 & 0.977 \\
Warm ischemia time & 0.006 & 0.819 \\
Intraoperative blood loss & $<0.001$ & 0.478 \\
\hline
\end{tabular}

We further investigated the influence of splenectomy on post-operative complications after LT, based on the Clavien-Dindo complication classification [21]. 21 deaths occurred in the 90 days after operation in either the $\mathrm{Sp}(-)$ or $\mathrm{Sp}(+)$ group, and no difference existed between the two groups with regard to various grades of post-operative complications and 90 days mortality. Settmacher et al. [22] reported that concomitant splenectomy during LT was associated with a significant and increased risk of venous complications, such as portal vein thrombosis. However, none of our liver transplant patients in whom splenectomy was performed prior to LT developed portal vein thrombosis. This is consistent with the reports of Hirotaka et al. [7] It is interesting that the incidence of one of the postoperative complications of LT, thrombocytopenia, decreased rather than increased in patients who underwent splenectomy. Many studies have found that the platelet count reaches a nadir at days $2-5$ post-transplant, but returned to preoperative levels by weeks 1-2 [23-26]. The reason for this remains unclear. Chang et al. [27] have found that persistent thrombocytopenia is an indicator of a higher rate of fungal infections in liver transplant recipients. On the other hand, platelet-derived serotonin has been found to be important for liver regeneration [28]. A retrospective study [29] has shown that transfused platelets are significantly associated with graft regeneration in liver donors. Furthermore, Bleibel et al. [30] recently observed that peripheral platelet count correlated with liver atrophy and predicted long-term mortality in patients on the liver transplant waiting list. Interestingly, splenectomy can increase the number of platelets, yet portacaval or distal splenorenal shunts cannot increase the number of platelets [31-33]. The reason for this may be that platelets participate in splenic destruction, rather than merely pooling in the spleen [34-36]. In our series of 162 post-matched patients, post-operative peripheral platelet levels were significantly higher $(P=0.041)$ in group $\mathrm{Sp}(+)$ than in group $\mathrm{Sp}(-)$. Therefore, we believe that splenectomy is an effective approach for increasing platelets. Furthermore, EAD is often used as the best choice of the primary outcome after LT. Li et al. [37] have conducted a retrospective study on adult-toadult living donor liver transplantation (A-A LDLT) and found that an immediate post-operative platelet count of less than $68 \times 10^{9} / \mathrm{L}$ was an independent risk factor for post-operative EAD. Interestingly, in our study the Group $\mathrm{Sp}(-)$ did have more EAD than $\mathrm{Sp}(+)(P=0.038)$. As for its reasons, we considered immediate postoperative low platelet mainly affected the recovery of the liver function by liver regeneration, because there was no significant difference between the two groups with regard to postoperative major complications. The results were also confirmed by us in the living donor liver transplantation [37]. But the specific mechanism still remained to be further studied in the laboratory. 
We also compared the overall survival rate of patients between the $\mathrm{Sp}(-)$ and $\mathrm{Sp}(+)$ groups. In the past, there had been many reports on the effects of LT after splenectomy or simultaneous splenectomy in liver transplant patients, but due to the small number of observations, the results were controversial. At present, there is a lack of a corresponding standard for patients who underwent splenectomy prior to liver transplant. In order to verify the effects of splenectomy on liver transplant patients, we here observed 820 patients in a 5-yearfollow-up study. After analyzing the cumulative overall survival rates of groups $\mathrm{Sp}(+)$ and $\mathrm{Sp}(-)$, we found no significant differences in the 1-, 3-, and 5-year survival rates in the post-match model. Therefore, we concluded that LT may be suitable for the patients who underwent splenectomy. However, well-designed, long-term, randomized, controlled, prospective trials are still necessary to confirm this proposal.

Through the above analysis, pre-transplantation splenectomy is recommended in cases with risky PHT patients without appropriate source of liver for LT. But one thing to note is that as a "re-operation" the splenectomy is often associated with more difficult dissection due to adhesions. We subjectively believed the transplant operation was perhaps more difficult in the splenectomy group. Although the average time spent on $\mathrm{Sp}(-)$ was less than group $\mathrm{Sp}(+)$, there was no statistic difference between operative times and intraoperative blood loss. Finally, we believe that adhesion does have some effect on group $\mathrm{Sp}(+)$, but it is not obvious.

Our study has several limitations. First, we performed our analysis using only about 82 cases in the $\mathrm{Sp}(+)$ group. The limited number of patients may underlie the lack of significant differences and a larger multicenter study should investigate this matter further. Second, these data were retrospectively collected and analyzed, and a prospective clinical investigation should be performed to evaluate the role of splenectomy in this context.

\section{Conclusions}

The results of the present study suggest that pretransplantation is a very effective method for the treatment of thrombocytopenia after ADLT. Moreover, compared with $\mathrm{Sp}(-)$, the risk of infection and post-operative complications in group $\mathrm{Sp}(+)$ is not increased, and group $\mathrm{Sp}(+)$ had a lower rate of post-operative EAD. There was no difference in the cumulative survival rates between the two groups. Pre-transplantation splenectomy is recommended in cases with risky PHT patients without appropriate source of liver for LT.

\section{Additional file}

Additional file 1: Table S1. Disease Features and Perioperative Characteristics of Splenectomy Patients ( $n=82)$. (DOC $34 \mathrm{~kb}$ )

\section{Abbreviations}

ADLT: Adult liver transplantation; AFP: Alpha-fetoprotein; AZA: Azathioprine; BCLC: Barcelona Clinic Liver Cancer; BMI: Body mass index; EAD: Early allograft dysfunction; GRWR: Graft/Recipient's Body Weight Ratio; HBV: Hepatitis B virus; HCC: Hepatocarcinoma; HCV: Hepatitis C virus; LT: Liver transplantation; MELD: Model for end-stage liver disease; PHT: Portal hypertension; Sp: Pretransplantation splenectomy; TB: Total bilirubin; UCSF: University of California San Francisco

\section{Acknowledgements}

We thank all patients and staff of our hospital who participated in this study.

Funding

This study was supported by grants from the National Natural Science Fundation of China (no. 81470037).

\section{Availability of data and materials}

All related data are stored in the Chinese Liver Transplant Registry (CLTR: http:// (Itr.cotr.cn). The data that support the findings of this study are available from the Chinese Liver Transplant Registry (CLTR: http://cltr.cotr.cn), but restrictions apply to the availability of these data, which were used under license for the current study, and so are not publicly available. But all related data in this study are available from the corresponding author on reasonable request.

\section{Authors' contributions}

$L K, L Y, L J$ and JY designed the study; $L L, M L$ performed the research and collected the data; LK, ML, LL analyzed and interpreted the data; LK wrote the first draft of the manuscript; All authors edited the manuscript and approved the final draft; The acquisition of funding is from JY.

\section{Competing interests}

The authors declare that they have no competing interests.

\section{Consent for publication}

Not applicable.

\section{Ethics approval and consent to participate}

In our study, the grafts for LT were from donation after cardiac death. No prisoners were included as donors. The protocol was approved by the Ethics Committee of the West China Hospital of Sichuan University West China Hospital. Written informed consent was obtained from all the recipients prior to their surgery, and all of donations were voluntary and altruistic in all cases, and were in accordance with the ethical guidelines of the Declaration of Helsinki.

\section{Publisher's Note}

Springer Nature remains neutral with regard to jurisdictional claims in published maps and institutional affiliations.

Received: 21 September 2016 Accepted: 12 April 2017

Published online: 20 April 2017

\section{References}

1. Chu H, Han W, Wang L, Xu Y, Jian F, Zhang W, et al. Long-term efficacy of subtotal splenectomy due to portal hypertension in cirrhotic patients. BMC Surg. 2015;15:89.

2. Wolff $M$, Hirner A. Surgical treatment of portal hypertension. Zentralbl Chir. 2005;130(3):238-45.

3. Starzl TE, Marchioro TL, Talmage DW, Waddell WR. Splenectomy and thymectomy in human renal homotransplantation. Proc Soc Exp Biol Med. 1963;113:929-32.

4. Troisi R, Colle I, Van Vlierberghe H, Hesse UJ, Cuomo O, de Hemptinne B. Splenectomy and liver transplantation. Transplant Proc. 2001;33(1-2):1500-1.

5. Stevenson WC, Sawyer RG, Pruett TL. Recurrent variceal bleeding after liver transplantation-persistent left-sided portal hypertension. Transplantation. 1992;53(2):493-5.

6. Ayalon A, Wiesner RH, Perkins JD, Tominaga S, Hayes DH, Krom RA. Splenic artery aneurysms in liver transplant patients. Transplantation. 1988:45(2):386-9.

7. Tashiro H, Itamoto T, Ohdan H, Fudaba Y, Kohashi T, Amano H, et al. Should splenectomy be performed for hepatitis $\mathrm{C}$ patients undergoing living-donor liver transplantation? J Gastroenterol Hepatol. 2007;22(6):959-60. 
8. Mazzaferro V, Regalia E, Doci R, Andreola S, Pulvirenti A, Bozzetti F, et al. Liver transplantation for the treatment of small hepatocellular carcinomas in patients with cirrhosis. N Engl J Med. 1996;334(11):693-9.

9. Yao FY, Ferrell L, Bass NM, Watson JJ, Bacchetti P, Venook A, et al. Liver transplantation for hepatocellular carcinoma: expansion of the tumor size limits does not adversely impact survival. Hepatology (Baltimore, Md). 2001;33(6):1394-403.

10. Zheng SS, Xu X, Wu J, Chen J, Wang WL, Zhang M, et al. Liver transplantation for hepatocellular carcinoma: Hangzhou experiences. Transplantation. 2008; 85(12):1726-32.

11. Llovet JM. Updated treatment approach to hepatocellular carcinoma. J Gastroenterol. 2005;40(3):225-35.

12. Louis D, Duc ML, Reix P, Chazalette JP, Durieu I, Feigelson J, et al. Partial splenectomy for portal hypertension in cystic fibrosis related liver disease. Pediatr Pulmonol. 2007;42(12):1173-80.

13. Dindo D, Demartines N, Clavien PA. Classification of surgical complications: a new proposal with evaluation in a cohort of 6336 patients and results of a survey. Ann Surg. 2004;240(2):205-13.

14. Santambrogio R, Kluger MD, Costa M, Belli A, Barabino M, Laurent A, et al. Hepatic resection for hepatocellular carcinoma in patients with Child-Pugh's A cirrhosis: is clinical evidence of portal hypertension a contraindication? HPB. 2013;15(1):78-84.

15. Olthoff KM, Kulik L, Samstein B, Kaminski M, Abecassis M, Emond J, et al. Validation of a current definition of early allograft dysfunction in liver transplant recipients and analysis of risk factors. Liver Transpl. 2010;16(8):943-9.

16. Huang F, Du C, Sun M, Ning B, Luo Y, An S. [Propensity score matching in SPSS]. Nan Fang Yi Ke Da Xue Xue Bao. 2015;35(11):1597-601.

17. Bisharat N, Omari H, Lavi I, Raz R. Risk of infection and death among postsplenectomy patients. J Infect. 2001;43(3):182-6.

18. Cescon M, Sugawara $Y$, Takayama T, Seyama $Y$, Sano K, Imamura H, et al. Role of splenectomy in living-donor liver transplantation for adults. HepatoGastroenterology. 2002;49(45):721-3.

19. Jeng LB, Lee CC, Chiang HC, Chen TH, Hsu CH, Cheng HT, et al. Indication for splenectomy in the era of living-donor liver transplantation. Transplant Proc. 2008;40(8):2531-3.

20. Shimada M, ljichi H, Yonemura Y, Harada N, Shiotani S, Ninomiya M, et al. The impact of splenectomy or splenic artery ligation on the outcome of a living donor adult liver transplantation using a left lobe graft. HepatoGastroenterology. 2004;51(57):625-9.

21. Clavien PA, Barkun J, de Oliveira ML, Vauthey JN, Dindo D, Schulick RD, et al. The Clavien-Dindo classification of surgical complications: five-year experience. Ann Surg. 2009;250(2):187-96.

22. Settmacher U, Nussler NC, Glanemann M, Haase R, Heise M, Bechstein WO, et al. Venous complications after orthotopic liver transplantation. Clin Transpl. 2000;14(3):235-41.

23. McCaughan GW, Herkes R, Powers B, Rickard K, Gallagher ND, Thompson JF, et al. Thrombocytopenia post liver transplantation. Correlations with preoperative platelet count, blood transfusion requirements, allograft function and outcome. J Hepatol. 1992;16(1-2):16-22.

24. Richards EM, Alexander GJ, Calne RY, Baglin TP. Thrombocytopenia following liver transplantation is associated with platelet consumption and thrombin generation. Br J Haematol. 1997;98(2):315-21.

25. Chatzipetrou MA, Tsaroucha AK, Weppler D, Pappas PA, Kenyon NS, Nery JR, et al. Thrombocytopenia after liver transplantation. Transplantation. 1999; 67(5):702-6.

26. Lesurtel M, Raptis DA, Melloul E, Schlegel A, Oberkofler C, El-Badry AM, et al. Low platelet counts after liver transplantation predict early posttransplant survival: the 60-5 criterion. Liver Transpl. 2014;20(2):147-55.

27. Chang FY, Singh N, Gayowski T, Wagener MM, Mietzner SM, Stout JE, et al. Thrombocytopenia in liver transplant recipients: predictors, impact on fungal infections, and role of endogenous thrombopoietin. Transplantation. 2000;69(1):70-5.

28. Lesurtel M, Graf R, Aleil B, Walther DJ, Tian Y, Jochum W, et al. Platelet-derived serotonin mediates liver regeneration. Science. 2006;312(5770):104-7.

29. Kim J, Yi NJ, Shin WY, Kim T, Lee KU, Suh KS. Platelet transfusion can be related to liver regeneration after living donor liver transplantation. World J Surg. 2010;34(5):1052-8.

30. Bleibel W, Caldwell SH, Curry MP, Northup PG. Peripheral platelet count correlates with liver atrophy and predicts long-term mortality on the liver transplant waiting list. Transpl Int. 2013:26(4):435-42.
31. Toghill PJ, Green S. Splenic influences on the blood in chronic liver disease. O J Med. 1979:48(192):613-25.

32. Mutchnick MG, Lerner E, Conn HO. Effect of portacaval anastomosis on hypersplenism. Dig Dis Sci. 1980;25(12):929-38.

33. Lawrence SP, Lezotte DC, Durham JD, Kumpe DA, Everson GT, Bilir BM. Course of thrombocytopenia of chronic liver disease after transjugular intrahepatic portosystemic shunts (TIPS). A retrospective analysis. Dig Dis Sci. 1995;40(7):1575-80.

34. Stein SF, Harker LA. Kinetic and functional studies of platelets, fibrinogen, and plasminogen in patients with hepatic cirrhosis. J Lab Clin Med. 1982;99(2):217-30

35. Schmidt KG, Rasmussen JW, Bekker C, Madsen PE. Kinetics and in vivo distribution of 111-In-labelled autologous platelets in chronic hepatic disease: mechanisms of thrombocytopenia. Scand J Haematol. 1985;34(1):39-46.

36. Aoki Y, Hirai K, Tanikawa K. Mechanism of thrombocytopenia in liver cirrhosis: kinetics of indium-111 tropolone labelled platelets. Eur J Nucl Med. 1993;20(2):123-9.

37. Li L, Wang H, Yang J, Jiang L, Yang J, Wang W, et al. Immediate postoperative low platelet counts after living donor liver transplantation predict early allograft dysfunction. Medicine. 2015;94(34):e1373.

\section{Submit your next manuscript to BioMed Central and we will help you at every step:}

- We accept pre-submission inquiries

- Our selector tool helps you to find the most relevant journal

- We provide round the clock customer support

- Convenient online submission

- Thorough peer review

- Inclusion in PubMed and all major indexing services

- Maximum visibility for your research

Submit your manuscript at www.biomedcentral.com/submit
C) Biomed Central 